\title{
ANOMALI HETERODOKSA DALAM PRAKTIK KOMUNIKASI KELOMPOK MANTONGAN PADA PRODUKSI GARAM RAKYAT DI SURABAYA
}

\section{Anomaly Heterodoxa through Group Communication: A Study of Community Salt Production in Surabaya}

\author{
Moch. Imron Rosyidi ${ }^{1, *}$, Budi Guntoro ${ }^{2)}$, Alia Bihrajihant Raya ${ }^{3)}$, Erwin Rasyid ${ }^{4)}$
}

\author{
${ }^{1}$ Program Studi Ilmu Komunikasi, Universitas Muhammadiyah Magelang, Magelang 56126, Indonesia \\ ${ }^{2}$ Fakultas Peternakan, Universitas Gadjah Mada, Yogyakarta 55281, Indonesia \\ ${ }^{3}$ Fakultas Pertanian, Universitas Gadjah Mada, Yogyakarta 55281, Indonesia \\ ${ }^{4}$ Program Studi Ilmu Komunikasi, Universitas Aisyiyah Yogyakarta, Yogyakarta 55292, Indonesia \\ ${ }^{*}$ E-mail: imron.rosyidi@ummgl.ac.id
}

\section{ABSTRACT}

People's salt production in Surabaya mainly relies on mantongan, a name for salt production labor in Madura. Mantongan experiences discrimination and pressure from its landlord and strives to resist the oppression. Pierre Bourdieu believes that the oppressor can practice a doxa to strengthen their position in the social structure. This doxa could only be diminished when a heterodoxa appeared. This study is aimed to analyze how heterodoxa and doxa operate in the habitus between mantongan and the landlord. This study uses qualitative method with a critical approach. The informant of this study are mantongan and landlord in Surabaya. Pierre Bourdieu's Social Practice is used as theory. This study shows that heterodoxa could only be achieved when the social structure dwindles. This finding contradicts Bourdieu's concept of heterodoxa. The group communication of community salt production, showed that mantongan is able to contest and rebel under the pressure of the landlord. The concept of doxa and orthodoxy here is no longer valid when mantongan is in its lowest point. This result is seen as an anomaly in Bourdieu's thought of social practice

Keywords : Anomaly, Community Salt Production, Group Communication, Heterodoxa

\begin{abstract}
ABSTRAK
Produksi garam rakyat di Surabaya mengandalkan mantongan yaitu buruh produksi garam asal madura sebagai ujung tombak produksi. Dalam praktiknya terdapat sebuah relasi sosial antara mantongan dengan juragannya hingga membentuk struktur sosial. Pierre Bourdieu berpendapat bahwa selalu terdapat Doksa untuk memperkuat kedudukan dalam struktur sosial, antara mantongan dan juragannya. Doksa tersebut akan hilang jika muncul suatu heterodoksa dalam suatu struktur masyarakat, dengan syarat struktur tersebut melemah. Penelitian ini ingin menganalisis bagaimana heterodoksa dan doksa beroperasi dalam habitus relasi komunikasi antara mantongan dengan juragannya. Penelitian ini menggunakan metode kualitatif dengan paradigma kritis. Informan dari penelitian ada para mantongan dan juragan di Surabaya. Landasan teori yang akan digunakan adalah praktik sosial menurut Pierre Bourdieu. Penelitian ini menunjukkan bahwa heterodoksa hanya akan dapat tercapai ketika kondisi struktur sosial melemah. Temuan ini berlawanan dengan konsep heterodoksa menurut Bourdieu. Dalam komunikasi kelompok pada penelitian ini, mantongan tetap dapat melakukan perlawanan di bawah tekanan juragannya. Konsep doksa dan ortodoksa disini tidak berlaku lagi ketika mantongan sudah dalam titik nadir. Temuan ini dilihat sebagai anomali dalam sebuah praktik sosial menurut Pierre Bourdieu.
\end{abstract}

Kata kunci : Anomali, Produksi Garam Rakyat, Komunikasi Kelompok, Heterodoksa

Content from this work may be used under the terms of the Creative Commons Attribution-ShareAlike 4.0 International License.. Any further distributionof this work must maintain attribution to the author(s) and the title of the work, journal citation and DOI.

Published under Department of Communication and Community Development Science, IPB University ISSN: 1693-3699 |EISSN: 2442-4102 


\section{PENDAHULUAN}

Kota Surabaya sebagai kota metropolis menyumbang 21.000 Ton produksi garam rakyat (Ardiyanti, 2016). Nilai itu setara dengan 5\% produksi garam di Jawa Timur, yang memenuhi $12 \%$ kebutuhan garam nasional (Kementerian Kelautan dan Perikanan, 2010). Data tersebut memperlihatkan bahwa produksi garam rakyat mempunyai sumbangsih besar dalam memenuhi kebutuhan garam nasional. Produksi garam rakyat adalah bagian dari agrokompleks. Pada sektor tersebut dibutuhkan sinergi antara kegiatan penyuluhan dan produksi untuk memenuhi kebutuhannya demi kedaulatan pangan (Udayan \& Sreedaya, 2018).

Garam sebagai sebuah komoditas masih menjadi polemik dari berbagai sektor dari hulu hingga hilir, mulai impor Produksi garam rakyat di Surabaya yang berfokus di wilayah Surabaya Barat, pada umumnya tidak diproduksi oleh masyarakat asli daerah tersebut dengan sistem tenaga buruh. Sistem tenaga buruh ini dirancang melalui adanya bagi hasil antara juragan dan buruh produksi garam ketika masa panen.

Para buruh produksi garam disebut sebagai mantongan, sebuah sebutan yang kerap diberikan pada penggarap lahan garam musiman. Mantongan berasal dari kata mantong yang berarti ladang garam dan mantongan berarti penggarap ladang garam (Prasetyo, 2017). Pelabelan ini bersumber pada status sosial mereka dan telah berlangsung lama (Kusuma, Hariadi, Subejo, \& Mudiyono, 2016). Mantongan umumnya datang dari wilayah Madura terutama wilayah Sumenep. Mereka mempunyai kemampuan khusus dalam membuat garam yang telahdipraktikkan selama bertahun-tahun. Mereka telah turun-temurun mewarisi keahlian sebagai seorang pembuat garamyang melalui proses cukup panjang dan membutuhkan kesabaran (Prasetyo, 2017).

Pada produksi garam rakyat, para petambak garam atau juragan juga memiliki andil yang cukup besar dalam produksi. Juragan adalah pemodal utama dalam produksi garam. Mereka menanggung biaya hidup mantongan, yaitu kurang lebih Rp 600.000,- dalam sepekan selama masa produksi (Prasetyo, 2017). Ketika musim kemarau tiba, mantongan akan datang menemui pemilik ladang di Surabaya untuk membuat kesepakatan antara mantongan dengan juragan dalam hal bagi hasil.

Proses pengupahan dalam produksi garam memakai sistem bagi hasil saat panen dengan mekanisme seperti gambar 1 di bawah. Dengan rincian mantongan mendapat sepertiga dari hasil panen, sisanya untuk juragan biasa disebut mekanisme sistem telon. Sebelum itu tentu harus dipotong dengan pinjaman biaya hidup yang diberikan sebelumnya. Selain itu juga terdapat mekanisme bagi hasil dengan sistem paron untuk mantongan yang memiliki modal produksi. Apabila kesepakatan dalam mekanisme telon antara mantongan dan juragan telah tercapai, para mantongan akan tinggal di sebuah gubuk yang didirikan di tengah ladang. Mantongan akan menjadi penanggung jawab atas produksi sampai garam siap dijual. Para juragan akan ikut campur atau bertanggung jawab pada saat proses jual beli garam (Prasetyo, 2017).

Dalam kajian pertanian hal ini sering disebut dengan Sistem Sakap (Rachmat \& Muslim, 2012). Sistem Sakap merupakan sistem kesepakatan bagi hasil diantara pemodal dan buruh tani (Nashruddin, 2016). Dalam sistem ini terdapat beberapa mekanisme misal Maro (bagi dua 1:1), Morotelu (bagi tiga 1:2), dan Moropapat (bagi empat 1:3). Dalam kasus antara mantongan dan Juragan tersebut menerapkan sistem Morotelu (bagi tiga 1:2). Hasil tersebut dipotong lagi uang pinjaman biaya hidup selama produksi garam mulai 300.000 hingga 600.000 Rupiah setiap pekan (Prasetyo, 2017). 


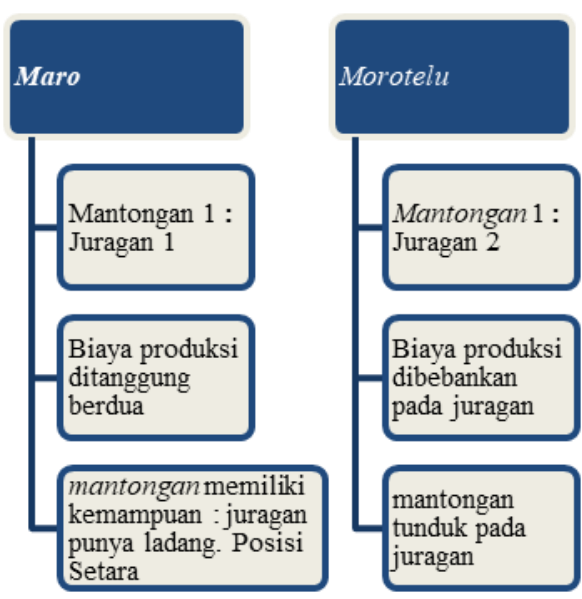

Gambar 1. Skema bagi hasil mantongan

Sistem bagi hasil mantongan yang dirancang memungkinkan munculnyarelasi yang tidak baik atau tidak seimbang antara juragan dan mantongan. Hal ini disebabkan karena adanya kemungkinan mantongan dirugikan dalam relasi ini (Rachmat \& Muslim, 2012). Ketidakseimbangan hubungan dalam relasi menunjukkan adanya kesalahan komunikasi dalam kelompok tersebut. Komunikasi itu bersifat sosial dan sosial itu bersifat komunikatif, maka semestinya komunikasi dapat menentukan relasi sosial (Hardt, 1993). Sejalan dengan itu segala sesuatu yang berhubungan dalam suatu kelompok, mestinya mengungkapkan bagaimana relasi sosial dipengaruhi atau tercipta dari komunikasi dan sebaliknya, Begitupun dalam komunikasi pada suatu kelompok, sehingga bentuk, isu dan pembicaraan akan menentukan dan ditentukan oleh relasi sosial. .Dalam Komunikasi Pembangunan penting untuk mengenal audiens, dengan mengenal audiens lebih dalam maka akan mudah merumuskan suatu strategi pembangunan atau program komunikasi yang efektif. Memahami masyarakat adalah kunci dari keberhasilan program komunikasi pembangunan. Dalam suatu kondisi ketika mekakukan program komunikasi pembangunan, akan menemukan struktur masyarakat yang mengekang. Hal tersebut dapat diatasi dengan cara pelaksana program 'mendengarkan' masyarakat marjinal (Dutta, 2014)

Pandangan ini merupakan upaya kritik terhadap struktur dominan dan mengekang kesempatan untuk mendengarkan sub-altern seperti petani serta kaum akar rumput lainnya yang selalu diposisikan sebagai objek pembangunan, yang tidak bisa apa-apa dan selalu membutuhkan bantuan (Dutta, 2014). Maka antara agen dan struktur pembangunan, harus bekerja bahu-membahu dan berkesinambungan, termasuk dalam upaya memahami kebutuhan dan problematika masayakat akar rumput. Sehingga setiap program pembangunan akan efektif dan menyasar tepat pada penyelesaian problematika masyarakat

Upaya yang paling bisa dilihat dalam memahami struktur masyarakat produksi garam yang ada di Surabaya adalah melalui bentuk komunikasi kelompoknya. Komunikasi kelompok terbagi menjadi dua kategori yaitu kelompok primer dan kelompok sekunder (Rakhmat, 2005). Kelompok primer merupakan kelompok yang anggota kelompoknya berhubungan akrab, personal, dan menyentuh hati para anggota kelompok tersebut, sedangkan kelompok sekunder merupakan kelompok yang anggota kelompoknya berhubungan tidak akrab, tidak personal, serta tidak menyentuh hati para anggota kelompok satu dengan yang lainya (Rosyidi, 2018).

Kajian mengenai komunikasi kelompok telah banyak dilakukan. Pada penelitian yang dilakukandi kelompok petani cabai lahan pasir di Kulonprogo, Daerah Istimewa Yogyakarta ditemukan bahwa pembangunan kelompok pertanian di Indonesia berjalan stagnan karena fungsi kelompok kurang bisa mengakomodasi kebutuhan anggota-anggotanya (Raya, 2016). Komunikasi kelompok antar petani atau peternak dan pelaku sektor agrokompleks lainnya adalah aktivitas yang paling sering dilakukan terutama di pedesaan (Matindas, Hubeis, \& Saleh, 2010). Oleh sebab itu siginifikansi penelitian mengenai praktik komunikasi kelompok memiliki posisi penting dalam komunikasi pembangunan, karena berkaitan dengan pembangunan keompok pertanian dan praktik yang paling banyak dilakukan di pedesaan. 
Dalam komunikasi kelompok terdapat yang disebut sebagai kuasa simbolik pada individu atau agen (Bataona \& Bajari, 2017). Kuasa simbolik tersebut dapat terdiri dari yang disebut sebagai doksa, ortodoksa, dan heterodoksa. Bourdieu menjelaskan bagaimana proses terjadinya kuasa simbolik dalam habitusmelalui apa yang disebutnya sebagai doksa, yakni seperangkat kepercayaan fundamental yang bahkan sampai dirasa tidak perlu dieksplisitkan, dipertanyakan lagi, atau dipertentangkan (Forchtner \& Schneickert, 2016). Dengan kata lain, secara sederhana doksa adalah suatu kepercayaan yang diterima apa adanya, tidak pernah dipertanyakan, yang telah mengarahkan cara pandang seseorang dalam mempersepsi dunia atau bidang di mana doksa tersebut berada. Hal tersebut dalam kalimat singkat Bourdieu: the universe of the undiscussed atau "semesta yang tak terdiskusikan"(Savage \& Silva, 2013). Dutta dalam sebuah penelitian di India menunjukkan bahwa gagalnya upaya korporasi benih akibat dari terancamnya kedaulatan benih masyarakat petani, mereka tidak diajak berkomunikasi untuk memikirkan solusinya. Hal itu memicu petani melakukan perlawanan kooptasi alternatif dengan memepertahankan penggunaan benih sendiri. Fenomena itu menunjukkan bahwa kesalahan program pembangunan selain tidak 'mendengarkan' akar rumput, namun juga terjadinya dominasi sumberdaya (Dutta, 2011). Hal tersebut tidak hanya berakibat pada tidak berjalannya program pembangunan, namun juga menekan posisi kaum marjinal. Pemikiran dari hasil penelitian Dutta setidaknya memberikan gambaran bahwa dominasi ekonomi juga akan memicu dominasi komunikasi.

Proses perlawanan kuasa simbolik biasanya terjadi saat otonomi melemah sehingga memungkinkan munculnya pemikiran lain, yang memungkinkan disampaikan agen-agen dalam ranah tersebut untuk mempertanyakan, menantang, atau bahkan menggantikan doksa yang dimaksud diatas (Bataona \& Bajari, 2017). Pada titik ini, Bourdieu menyebut mengenai konsep heterodoksa dan ortodoksa. Pemikiran "yang menantang" atau mempertanyakan doksa disebut sebagai heterodoksa; yaitu pemikiran atau gagasan yang disampaikan secara eksplisit dan mempertanyakan sah atau tidaknya skema persepsi dan apresiasi yang tengah berlaku (Adib, 2012). Ortodoksa merujuk pada situasi di mana doksa dikenali dan diterima dalam praktik (Bourdieu, 2017), dengan kata lain, kelompok dominan yang memiliki kuasa berusaha mempertahankan struktur ranah yang didominasinya dengan memproduksi ortodoksa (Krisdinanto, 2016).

Berbagai macam penelitian mengenai komunikasi kelompok dan praktik sosial Bourdieu telah dilakukan. Seperti bagaimana operasionalisasi teori Bourdieu dalam penelitian tentang vespa gembel dengan judul Gaya Hidup Komunitas Penggemar Vespa Gembel Sebagai Subkultur (Studi Kasus di Bangkalan, Madura), penelitian tersebut menguji modernitas di tengah tradisionalitas (Rachmad, 2018). Berbeda dengan penelitian ini yang bertujuan menjelaskan tradisionalitas di tengah modernitas, penelitian tersebut juga menggunakan metode etnografi dan dirasa kurang menguak fenomena yang perlu dikritisi. Selanjutnya penelitian dengan judul Healthcare Choice: Bourdieu's Capital, Habitus and Field memiliki perbedaan tidak ada unsur komunikasi dalam kelompok dan hanya berfokus pada Bourdieu. Penelitian tersebut juga tidak menggunakan metode kritis. Hanya berfokus pada pilihan tidak sampai pada bagaimana Habitus terbentuk (Collyer, Willis, Franklin, Harley, \& Short, 2015).

Dari kajian literasi tersebut posisi penelitian ini masih baru dan belum ada yang pernah meneliti. Kebaharuan tersebut dilihat baik dari sisi lokasi, teori serta metode yang digunakan. Pendekatan kritis dan teori yang akan peneliti gunakan sangat dibutuhkan untuk tujuan melihat bagaimana heterodoksa dan doksa beroperasi dalam habitus relasi komunikasi antara Mantongan dengan Juragannya. Keunikan Critical Approach adalah menjelaskan fenomena untuk menembus permukaan (Neuman, 2013). Pendekatan ini tentu sangat penting dalam kajian pembangunan.

\section{METODE}

Penelitian ini menggunakan pendekatan. Bourdieu mengungkapkan bahwa penelitian sosial kritis mampu menggambarkan secara reflektif masalah sosial dalam masyarakat. Penelitian dengan paradigma kritis dapat menjembatani antara ide seseorang dengan realitas yang sebenarnya (Forchtner \& Schneickert, 2016; Neuman, 2013). Hal ini yang disebut Bourdieu dalam menjembatani pertentangananeh antara objektivisme dan subjektivisme. Penelitian komunikasi pembangunan juga diperlukan penelitian yang menggunakan pendekatan studi krisis. Ketika penelitian mampu menggambarkan fenomena yang terjadi pada masyarakat akar rumput, maka paradigma kritis sangat berguna untuk memberikan pertimbangan kebijakan pembangunan (Bataona \& Bajari, 2017). 
Penelitian inimengkontestasikan data antara informan mantongan dan juragannya. Pemilihan informan melalui teknik purposif dengan kriteria mantongan dan juragan yang telah tinggal minimal lima tahun di Surabaya. Lima tahun menjadi indikasi bahwa informan telah menjadi insider pada suatu struktur masyarakat (Geertz, 1976), begitu pula dalam struktur masyarakat pada kegiatan produksi garam. Jumlah masing-masing baik dari mantongan dan juragan adalah empat orang yang mewakili setiap kelurahan dimana produksi garam dilaksanakan, yakni Kelurahan Pakal, Kelurahan Sumberejo, Kelurahan Romokalisari, dan Kelurahan Sememi.

Data dikumpulkan melalui wawancara, observasi dan dokumentasi. Teknik-teknik ini digunakan untuk menjaga keabsahan data, karena dalam penelitian kualitatif peneliti adalah instrumen dari penelitian itu sendiri, sehingga dikhawatirkan terjadi bias data jika hanyalmenggunakan satu teknik pengambilan data. Observasi dilakukan selama kurang lebih dua bulan, yaitu antara 29 April 2018 sampai 15 Juli 2018. Peneliti merupakan warga asli di Kecamatan Pakal, sehingga dapat dengan mudah mengambil data yang representatif dalam penelitian ini.

Analisis data dilakukan dalam dua tahap, yaitu analisis data di lapangan dan analisis data pasca lapangan. Analisis data di lapangan dilakukan dengan mengembangkan pertanyaan bersifat analitis yang akan menguji keterkaitan subyek dengan fokus yang sedang diuji. Data yang diuji di lapangan adalah melakukan wawancara dengan menggunakan panduan wawancara, kemudian data dikontestasikan, dan dikritik dengan data dari informan lain serta teknik pengambilan data lainnya. Analisis data pasca lapangan dilakukan mereduksi data, menyajikan data, dan menarik kesimpulan berdasarkan fenomena yang dikaji.

\section{HASIL DAN PEMBAHASAN}

\section{Praktik Komunikasi Kelompok dalam Produksi Garam Rakyat}

Praktik bagi hasil antara mantongan dan juragan menentukan bagaimana relasi dan berimbas pada bentuk komunikasinya. Komunikasi kelompok antara mantongan dan juragan berlangsung dalam dua mekanisme, yakni mekanisme paron dan telon (Gambar 1). Dalam kondisi komunikasi yang demikian relasi antara juragan dan mantongan berjalan berbeda dalam kedua sistem. Ketika dalam sistem telon juragan jauh lebih dominan daripada mantongan. Pada sistem paron juragan cukup setara dengan mantongan jika dilihat dalam bentuk komunikasi yang terjadi. Hal tersebut menjadikan munculnya relasi kuasa simbolik.

Perbedaan itu menyangkut perbedaan bentuk komunikasi dalam berbagai isu seperti, piutang, gaji, bagi hasil tidak menjadi pembicaraan pada sistem telon. Sedangkan dalam sistem paron justru menjadi isu pembicaraan utama. Hal itu menentukan dominasi pada relasi antara mantongan dengan juragannya.

Tabel 1. Bentuk Komunikasi Kelompok dalam Produksi Garam Rakyat

\begin{tabular}{lll}
\hline No & \multicolumn{1}{c}{ Bentuk } & \multicolumn{1}{c}{ Isu Komunikasi / Dalam Kondisi } \\
\hline 1 & Bentuk Komunikasi Sekunder & Produktifitas, Bahasa, Terjadi dalam Sistem telon \\
2 & Bentuk Komunikasi Primer & Piutang, Gaji, Bagi hasil, Banyak terjadi dalam sistem paron \\
3 & Relasi & $\begin{array}{l}\text { Relasi dalam sistem telon juragan lebih dominan, Relasi } \\
\text { dalam sitem paron sama-sama dominasi }\end{array}$ \\
\hline
\end{tabular}

Dalam pemikiran Mohan Dutta (2011), distribusi ekonomi sejalan dengan ditribusi komunikasi. Pendapat tersebut sesuai dengan realita bahwa, mantongan meskipun memiliki keterampilan tetapi secara ekonomi mereka lemah. Sehingga isu yang berkaitan dengan kesejahteraan mereka jarang menjadi pembicaraan dalam relasi antara mantongan dengan juragannya. Dominasi itu semakin kuat, saat ditambah dengan stereotipe bahwa mantongan yang secara kultur dianggap sebagai masayarakat marjinal oleh warga setempat.

\section{Stereotipe dalam produksi garam rakyat}

Masyarakat yang memproduksi garam di Surabaya umumnya adalah masyarakat etnis Jawa Arekan sebagai juragan dan masyarakat Madura Sumenep sebagai penggarap atau buruh produksi. Hubungan antara juragan dan mantongan sudah berlangsung cukup lama bahkan ada yang sudah 
berhubungan kerja selama 22 tahun. Secara umum, relasi juragan dan mantongan memang telah terjalin lama dan berkesinambungan pada setiap musim produksi.

Hubungan antara etnis Jawa Arekan dan Madura dalam masa produksi garam dilakukan dengan menggunakan bahasa jawa Ngoko atau Arekan. Para mantongan terbiasa menggunakan bahasa jawa Ngoko atau Arekan (Sasongko, 2015), yaitu bahasa jawa khas Jawa Timur yang biasa dituturkan dalam kehidupan sehari-hari. Bahasa Madurahanya digunakan dengan keluarga dan sesama mantongan.

Mantongan yang merupakan masyarakat etnis Madura banyak mendapatkan stereotipe negatif oleh masyarakat setempat. Seperti banyak orang Jawa, penduduk asli Surabaya Barat sering kali tidak bisa membedakan mantongan dengan pemulung, karena sebagian kecil mantongan yang bergubuk (Gambar 2) di sekitar TPA Benowo memang memiliki pekerjaan sampingan sebagai pemulung(Kusuma et al., 2016). Penduduk asli sekitar Kecamatan Pakal dan Kecamatan Benowo pun menyebut pemulung dengan sebutan mantongan'. Hal ini menunjukkan bahwa bagi penuk sekitar, status mantongan tak ada bedanya dengan pemulung.

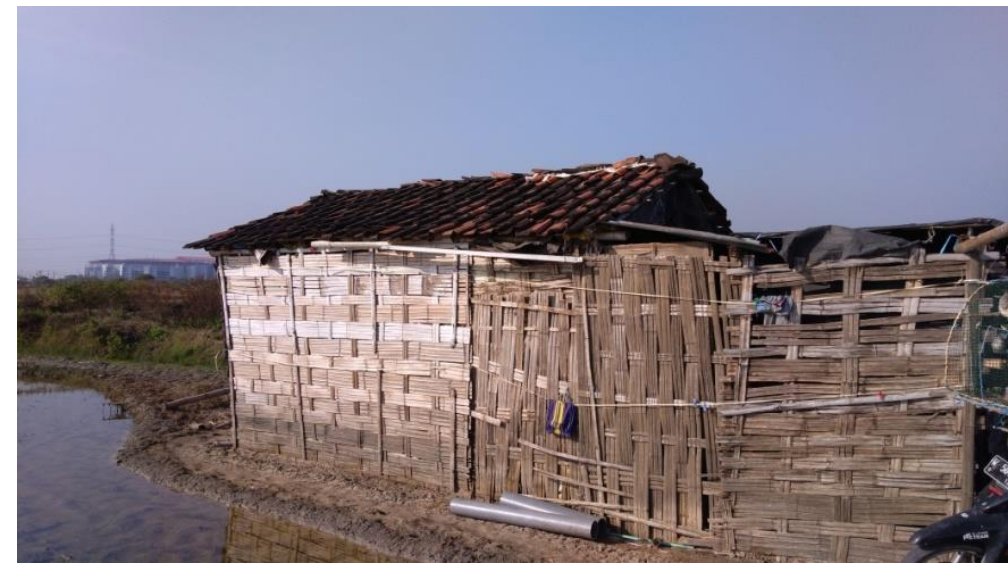

Gambar 2. Gubuk Tempat Tinggal Mantongan (terlihat stadion Bung Tomo dari Kejauhan)

Stereotipe mengenai masyarakat Madura yang keras, hidup di tempat kumuh, serta suka mencuri adalah pemahaman yang tertanam pada masyarakat Surabaya. Stereotipe ini memunculkan ketidakpercayaan juragan terhadap kerja mantongan, sehingga ketika musim produksi seorang juragan datang ke ladang 3 kali sehari untuk mengawasi mantongan. Seperti pernyataan seorang mantongan bernama Pak Juwito dalam kutipan berikut:

'Wah nek wak kaji sampai peng telu mas sedino nang kene, kadang yo wegah mosok wong kerjo ditunggoki terus. Tapi yaopo maneh mas karo jeragan yo nurut ae lah. Mon apel tak sopan ruah, kadang sampek peng papat sedino, wedi tak colong paling uyahe' (Surabaya/25/06/18)

'Wah kalau pak haji sampai tiga kali sehari datang ke ladang. Kadang ya merasa risih masak orang kerja ditunggui terus. Tapi kalau sama juragan mau bagaimana lagi ya harus nurut. Kalau mau protes kan tidak sopan mas, kalau parah kadang sampai empat kali sehari, mungkin takut saya curi garamnya.

Juragan menyatakan bahwa para mantongan sering bersikap kurang jujur. Juragan juga berargumen bahwa mereka harus menanggung resiko hasil, karena ketika musim penghujan tidak tentu dan mengakibatkan gagal panen, mantongan tidak perlu mengembalikan uang pinjaman untuk biaya hidup per minggu. Kondisi ini membuat juragan ingin memastikan bahwa mantongan tidak jujur dalam memproduksi garam. Diceritakan oleh para jurangan, bahwa para mantongan kerap kali mencuri beban garam ketika hendak diukur dengan timbangan. Semisal kesepakatan pemilik ladang dengan mantongan satu karung adalah $55 \mathrm{Kg}$, maka oleh mantongan hanya diisi $49-51 \mathrm{Kg}$. Hal tersebut seperti yang dituturkan oleh $\mathrm{H}$ Kholiq, selaku ketua kelompok Pugar Sumber Rejeki (Surabaya/30/06/18): 
"Ya gitu mas tapi kadang ada yang megikhlaskan atau potong separuh ketika gagal panen. Begitu mantongan masih tidak punya terimakasih. Timbangan tidak ditambah beratnya, pulang minta televisi, kulkas dan lain-lain. Memang susah kalau sama Madura itu mas, sebenernya ada Madura baik yang sampai 19 tahun kerja dengan saya. Sampai anaknya kerja ikut saya dan anaknya meninggal mendahului orangtuanya, sekarang tinggal ibunya dan bilang lelah mau pulang ke Sumenep.

Kalau yang ikut saya sekarang ini kan sudah empat tahun. Kerja kurang giat mintanya anehaneh. Saya sendiri kurang percaya bekerja dengan orang yang sedemikian itu.

Jadi kan satu karung itu $50 \mathrm{Kg}$ mas, karungnya kan $1 \mathrm{Kg}$ sendiri, yang kerja sama saya selama 19 tahun itu ditimbang $59 \mathrm{Kg}$, susut beratnya paling sisa $50 \mathrm{Kg}$. Nah sekaang minta $53 \mathrm{Kg}$ Cuma diisi $51 \mathrm{Kg}$ susut beratnya sisa $45 \mathrm{Kg}$ saya ya rugi terus mas. Ditambah pasang surut air ndak jelas mesti pakai solar buat diesel. Apa ndak nambah biaya saya.

Pernyataan tersebut menunjukkan bahwa ada stereotipe buruk kepada mantongan terlepas benar atau tidaknya suatu peristiwa. Masyarakat Madura memang telah mendapat label yang kurang baik dari penduduk sekitar. Hasil observasi juga menunjukkan banyak masyarakat Benowo Surabaya yang menggunakan mantongan sebagai subjek peringatan untuk anak-anak mereka agar tidak bermain jauh-jauh dari rumah. Ketakutan yang disalurkan adalah, ketika mereka bermain jauh maka, mereka bisa diculik mantongan. 'Ojo dolan adoh-adoh, ngko dicolong mantongan (pemulung) ibuk gak due anak Rek'. Mantongan dalam hal ini bukanlah arti sebenarnya, namun mantongan yang dikonotasikan dengan pemulung. Label mantongan sebagai buruh produksi garam telah mengalami bias menjadi pemulung yang berbahaya dan perlu diwaspadai keberadaaanya.

\section{Adanya Anomali Heterodoksa}

Masalah terpenting dalam produksi garam di Surabaya bukan pada penggunaan teknologi tepat guna atau hal aplikatif lainnya. Penelusuran mendalam melalui observasi dan wawancara menunjukkan kuasa simbolik menjadi masalah yang sangat berpengaruh dalam produksi garam rakyat di Surabaya. Mereka belum berani memunculkan konflik tersebut hingga permukaan. Pada konsep Bourdieu, mereka masih terkekang ortodoksa dalam hal ini oleh doksa juragan. Masyarakat Madura memiliki karakter yang sudah terbiasa biasa mengalami hubungan patron-klien dalam kehidupan di Madura (Hefni, 2012), walau begitu masyarakat madura bisa saja melawan untuk tidak berada dalam hubungan patron-klien.

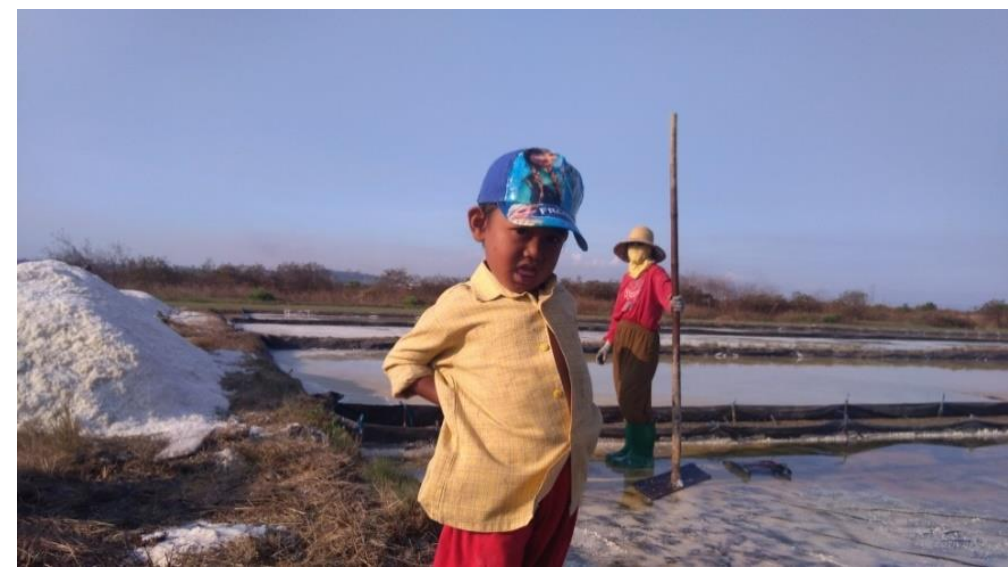

Gambar 3. Anak mantongan yang ikut dalam kegiatan produksi garam

Para mantongan yang seharusnya ketika masa produksi menjadi tanggung jawab juragan, justru banyak yang didiskriminasi dan dibiarkan ketika mereka mendapat kesusahan atau tertimpa musibah. Bahkan, menurut penuturan informan dari hasil wawancara ada yang sampai dibiarkan sakit dan meninggal dunia di gubuk mereka. Hal tersebut diakibatkan karena juragan tidak memberi pinjaman atau biaya berobat meskipun mantongan tersebut sakit ketika masa produksi.

Pernah, saudara saya, sakit di sini sampai meninggal, Mau pinjam uang 1 juta nggak dikasih 
(Sama Juragan). Pinjam nggak minta, pinjam!!!. Pinjam, nanti kan dipotong. Nggak dikasih sampai meninggal itu, iya, Kakaknya Buhara yang perempuan, sampai muntah-muntah darah di gubugnya itu. Sama mantongangannya kayak gitu. Parah. (07/07/18, Juwito)

Iya, nang kono, melok Haji. Loro, nyeleh duwek, gak dikek-dikeki tapi dipotong nang bayaran, duduk nganu iku, langsung bayar iso yo gak ono bayaran dipotong, dipake itu. Nang marani Rumah Sakit lah pirang, rong dina, petang dino malah. Lha kita ne, nggolek usaha seng nekuni temenan, mbiayai. Mari iku, wes leren, mari leren ndek cekel meh cerito, duite yo ngono yoan, totalan ngisore umum, dipotong iki, potong iki, padahal niku nek wes totalan yo onoke yo iku. Tapi nek sesuk, onone sambatan yo entek ngomonge.(13/07/18 Buhara).

Iya disana iku Haji. Sakit, ndak pegang uang ndak dikasih, dikasih tapi di potong mingguan. Jadi ya gak bisa dibawah ke rumah sakit dua hari sudah ndak sempat (meninggal). Setelah itu berhenti keluarganya sudah ndak pegang garam lagi. Dia itu ya gitu totalan harga terendah, dibawah harga umum. Dipotong ini dipotong itu, padahal harusnya ya adanya totalan ya itu. Gitu besok-besok adanya keluhan mantongan habis ngomongya (uangnya).

Kejadian tersebut menjadi titik nadir para mantongan. Mereka menganggap juragan yang sudah sampai membiarkan mantongan meninggal sudah di luar batas kewajaran hubungan patronklien. Hubungan patron-klien tanpa diperkuat kelembagaan memang cukup beresiko baik dari sisi buruh maupun juragan (Susilowati, 2016). Para mantongan pun memutuskan untuk melawan secara laten dari peristiwa ini. Perlawan dilakukan dengan merusak alat produksi, seperti memotong terpal (geomembran) yang berharga hingga 8 juta rupiah per petak.

Perlawanan lainnya adalah memutus hubungan mantongan-juragan karena tidak ada lagi mantongan yang mau bekerja kepada juragan tersebut pada produksi selanjutnya. Akhirnya, banyak ladang yang disewakan ke juragan lain. Jika semua mantongan di Surabaya berfikir demikian maka bukan tidak mungkin produksi garam di Surabaya akan semakin terancam eksistensinya.

Saya agak keras, kalau juragan, Haji itu, sampai tengkaran sama saya. Sampai sempat nggak akur satu (musim), 4 bulan sampai pulang nggak akur. Tapi uang bayaran dikasih, kalau nggak dikasih lain lagi caranya nanti. Saya kerja kok, kan gitu kan?. Gara-gara, iya bayaran itu, sering lambat. Nomor satu bayaran jangan lambat, kalau Mantongan itu. (07/07/18, Juwito)

Iya, kayak, wak Haji itu waduh, kadang sudah ada sudah biarin itu Mantongannya, kadang ada terpal (geomembran), langsung pakai arit gitu, dirusak sama Mantongannya, lah sudah keterlaluan. (07/07/18, Juwito).

Totalan, langsung disangu (saat kembali ke Madura) kui enak, tapi nek sek mbulet-mbulet, wes gak nemu wong, kangelan. nek memange Mantongan kadung mangkel iku, mbuh ya iku, lak seng disek suwek terpale. Wes apal temoni wes leren ngene wes itungane. (13/07/18 Buhara). Totalan langsung dikasih itu enak. Tapi kalau masih rumit-rumit, tidak bakal ada orang yang mau ikut, kesusahan. Kalau memang Mantongan terlanjur emosi. Ya ndak tau, itu contohnya disobek terpalnya. Geomembran. Sudah hafal maleslah ikut-ikut lagi.

Gak ono seng garap sebelah kene saiki.Wong iki enek jarakan, nek jarakan iwuh aturan ya, angel-angel tak jukuk menang karepe dewe, sangkane wong Mantongan koyok dolenan.(13/07/18 Buhara)

Gak ada yang mau garap lahan Haji. Dia sangat berjarak dengan bawahan. Aturannya susah juga. Susah-susah diambil (jalan tengah) mau menang sendiri. Dia mengira Mantongan sepeti mainan.

Penindasan terhadap mantongan merupakan konsekuensi dari stereotipe yang terbentuk oleh budaya setempat. Mantongan diidentikkan dengan kaum kelas bawah dan kaum pencuri, sehingga perilaku diskriminasi dianggap wajar oleh para juragan. Mereka sangat khawatir dengan tindakan buruk para mantongan yang berasal dari etnis Madura, sehingga memunculkan prasangka-prasangka buruk terhadap mereka. Orang Madura dengan kultur kerasnya sebenarnya tidak ingin untuk didiskriminasi secara demikian, namun kondisi ekonomi memaksa mereka untuk tetap tunduk dibalik doksa para juragan. Terbukti bahwa konflik-konflik yang tidak dimunculkan ke permukaan menjadi suatu konflik skala besar. Konflik Sampit-Madura pada tahun 2000-an juga bermula dari konflik 
individu kecil dan melebar menjadi konflik kelompok bahkan etnis (Mary, 2014). Pada kasus ini, para mantongan telah berani melawan dengan merusak alat produksi dan memutus hubungan patron-klien.

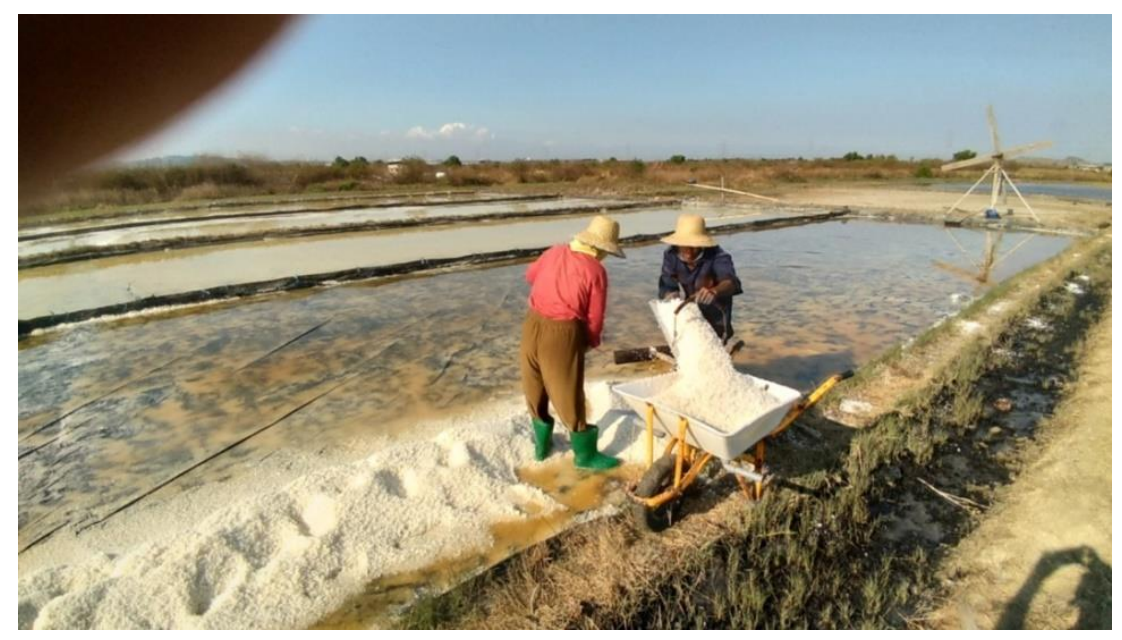

Gambar 4. Mantongan Memanen Garam di Atas Geomembran

Konflik hingga memotong geomembran seharga puluhan juta rupiah, serta tidak ada mantongan yang mau menggarap lahannya merupakan hal yang tidak pernah diinginkan para juragan. Pemilik modal mempunyai peran dan posisi yang sangat sentral dalam produksi ini. Akan tetapi dalam praktiknya kesejahteraan mantongan sebagai ujung tombak produksi garam merupakan hal yang sangat perlu diperhatikan.

Kejadian tersebut menjadi titik nadir para mantongan. Mereka menganggap juragan yang sudah sampai membiarkan mantongan meninggal sudah di luar batas kewajaran hubungan PatronClient. Hubungan Patron-Client tanpa diperkuat kelembagaan memang cukup beresiko baik dari sisi buruh maupun juragan (Susilowati, 2016). Makna keluarga dan saudara satu suku di masyarakat Madura sangat dalam. Terutama pada filosofi Taretan Dhibbik yang berarti persaudaraan sejati (Hefni, 2012). Itulah yang memperkuat mantongan dalam melakkan perlawanan ketika mereka merasa salah satu saudaranya tersakiti.

Kejadian itu telah menjadi titik balik perlawanan para mantongan secara latent. Akibatnya beragam, hingga perusakan alat produksi dan kerugian lain yang diterima juragan tersebut, berupa tidak ada mantongan yang mau bekerja kepadanya pada produksi selanjutnya. Masyarakat madura memiliki karakter yang biasa mengalami hubungan Patron-Client sejak dalam kehidupan di Madura (Hefni, 2012). Bukan tidak mungkin mereka akan semakin selektif dalam menjalin hubungan.

Bourdieu menjelaskan dalam setiap struktur yang kuat terdapat doksa berupa budaya yang terbentuk atau membentuk struktur tersebut, yang bila terwujud dalam praktiknya menjadi ortodoksa yang sudah tidak dapat lagi dirubah (Bataona \& Bajari, 2017). Hanya saja, ketika struktur melemah maka akan memunculkan kesadaran untuk bebas dari belenggu doksa dan hal ini disebut sebagai heterodoksa. Proses munculnya heterodoksa selalu dimulai dengan sadar, maka melalui komunikasi kelompok masyarkat mantongan berdiskusi secara terus-menerus. Proses berdiskusi dan belajar yang terus berlangsung membuat setiap orang memahami bahwa masing-masing mereka memiliki potensinya masing-masing (Rasyid, Adriyani, \& Darmawan, 2019).

Konsep Bourdieu menyatakan bahwa heterodoksa akan dapat tercapai ketika kondisi struktur sosial melemah (Nolan, 2012). Sejatinya pemahaman bahawa heterodoksa adalah pemikiran "yang menantang" atau mempertanyakan tersebut digunakan dalam mengupas fenomena perlawanan masayarakat terhadap suatu struktur. Untuk memudahkan pemahamannya maka dibuatkan gambar berikut. 


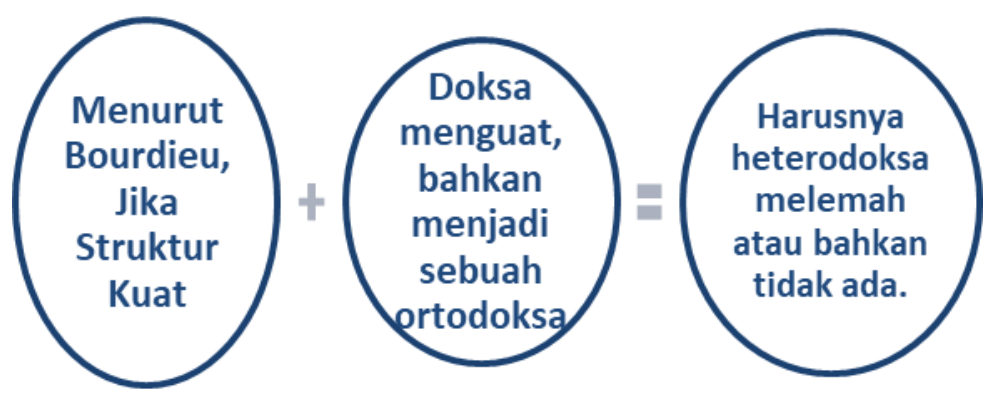

Gambar 5. Konsep Hetrodoksa Menurut Bourdieu

Berdasarkan Gambar 5 diatas, idealnya heterodoksa tidak akan menguat atau tidak muncul ketika struktur dan doksa menguat. Hal itu yang membuat seseorang atau masyarakat manjadi memiliki habitus tertentu pada sebuah arena (Wacquant, 2016). Penelitian ini menemukan kenyataan yang bertentangan dengan pernyataan tersebut. Tekanan atau kekuatan dari juragan justru mendorong mantongan untuk melakukan awanan secara implisit. Konsep doksa dan ortodoksa tidak berlaku lagi ketika masyarakat sudah dalam titik nadir. Kombinasi struktur yang kuat dan posisi agen yang sangat ditekan, memungkinkan agen untuk melakukan heterodoksa atau perlawanan simbolik terhadap agen yang menguasai struktur. Heterodoksa justru muncul disaat kondisi mantongan berada dalam struktur dan doksa yang menguat, sehingga muncullah sebuah anomali heterodoksa.
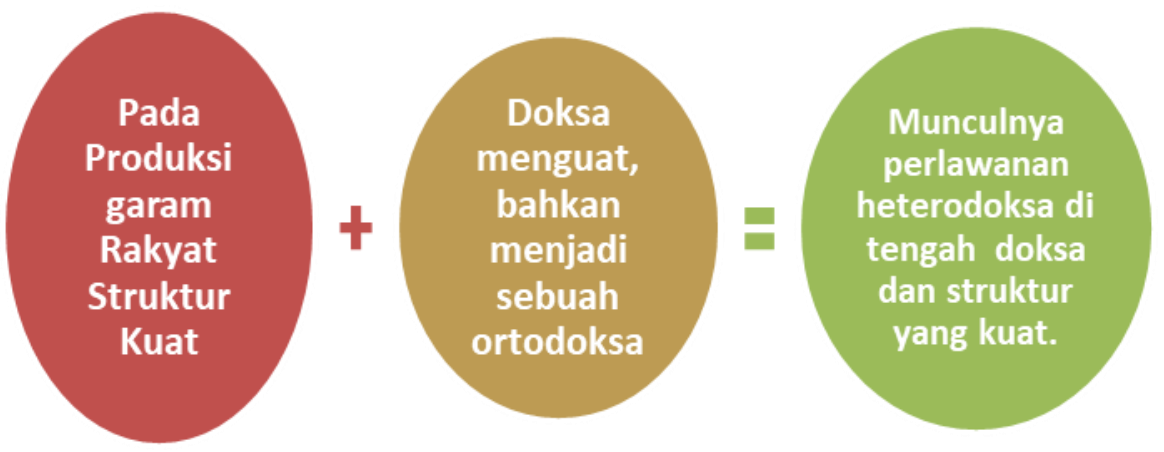

Gambar 6. Konsep yang tidak biasa dalam kekerasan simbolik

Konsep doksa dalam produksi garam ini berupa penegasan kuasa simbolik bahwa mantongan tidak mempunyai daya dan sangat membutuhkan juragan. Dalam konsep ortodoksa produksi garam, mantongan benar-benar alat buruh yang lemah dalam kuasa simbolik. Heterodoksa dalam titik nadir tersebut muncul ketika masyarakat mantongan dalam struktur terlemah dan juragan dalam kondisi terkuat pada konteks penguasaan modal dan aplikasi produksi. Akumulasi dari itu semua adalah kesadaran mantongan untuk melawan dan sadar akan posisi mereka sebagai ujung tombak produksi garam rakyat di Surabaya.

\section{KESIMPULAN}

Salah satu tujuan komunikasi pembangunan adalah keberdayaan masyarakat yang bisa dicapai dengan keadilan dalam setiap proses maupun pelaksanaannya. Hal tersebut bisa dicapai dengan keadilan atau kesetaraan antar elemen pembangunan dalam menciptakan proses komunikasi yang efektif. Relasi juragan dan mantongan belum berjalan dengan adil, serta masih menunjukkan tendensi kuasa simbolik dari stereotip buruk yang terbentuk. Pada praktiknya derajat kesetaraan komunikasi kelompok pada produksi garam rakyat di Surabaya belum terjadi, terutama dalam sistem telon. Derajat kesetaraan tidak terjadi dalam komunikasi kelompok pada produksi garam rakyat di Surabaya berhubungan dengan stereotip dan hubungan patron-klien antara mantongan dengan juragan. 
Proses komunikasi kelompok yang terjadi terus seperti itu pada produksi garam rakyat akan terus mengakibatkan konflik. Konflik-konflik kecil jika dibiarkan akan terjadi konflik yang lebih besar. Hal tersebut akan mengakibatkan keberlanjutan produksi garam rakyat semakin terancam.

Pengembangan wacana perlawanan atau heterodoksa memang telah terbentuk pada beberapa mantongan, namun belum terjadi secara eksplisit, sehingga mereka hanya melakukan perlawanan simbolik. Sistem bagi hasil sepertiga memang menguntungkan mantongan dari sisi resiko, namun mereka menjadi tidak memiliki daya tawar terhadap pemilik lahan. Hal ini menjadi perhatian ulang dalam merumuskan mekanisme pengupahan. Di sisi lain, beberapa sistem paron belum bisa diaplikasikan banyak mantongan karena terkendala dana dan resiko yang cukup besar. Mantongan melakukan perlawanan dalam tekanan juragannya. Konsep doksa dan ortodoksa disini tidak berlaku lagi ketika mantongan sudah dalam titik nadir. Hasil tersebut menjadi sebuah anomali dalam sebuah praktik sosial menurut Pierre Bourdieu.

\section{DAFTAR PUSTAKA}

Adib, M. (2012). Agen dan Struktur dalam Pandangan Piere Bourdieu. BioKultur, I(2), 91-110.

Ardiyanti, S. T. (2016). Produksi Garam Indonesia. In Z. Salim \& E. Munadi (Eds.), Info Komoditi Garam (pp. 7-30). Jakarta: Badan Pengkajian dan Pengembangan Perdagangan.

Bataona, M. R., \& Bajari, A. (2017). Power Relation and Symbols of Political-Economy of the Church in Local Political Contestation of East Nusa. Jurnal Kajian Komunikasi, 5(2), 121-135.

Bourdieu, P. (2017). Habitus. In J. Hillier \& E. Rooksby (Eds.), Habitus: A Sense of Place (2nd ed.). London: Routledge.

Collyer, F. M., Willis, K. F., Franklin, M., Harley, K., \& Short, S. D. (2015). Healthcare choice: Bourdieu's capital, habitus and field. Current Sociology, 63(5), 685-699. https://doi.org/10.1177/0011392115590082

Dutta, M. J. (2011). Communicating social change: Structure, culture, and agency. Routledge.

Dutta, M. J. (2014). A culture-centered approach to listening: Voices of social change. International Journal of Listening, 28(2), 67-81.

Forchtner, B., \& Schneickert, C. (2016). Collective learning in social fields: Bourdieu, Habermas and critical discourse studies. Discourse and Society, 27(3), 293-307. https://doi.org/10.1177/0957926516630892

Geertz, C. (1976). The religion of Java. Chicago: University of Chicago Press.

Hardt, H. (1993). Authenticity, communication, and critical theory. Critical Studies in Media Communication, 10(1), 49-69. https://doi.org/https://doi.org/10.1080/15295039309366848

Hefni, M. (2012). Patron-Client Relationship Pada Masyarakat Madura. KARSA: Journal of Social and Islamic Culture, 15(1), 15-24. https://doi.org/10.19105/karsa.v15i1.110

Kementerian Kelautan dan Perikanan. (2010). Kelautan dan perikanan dalam angka. Jakarta.

Krisdinanto, N. (2016). Pierre Bourdieu, Sang Juru Damai. KANAL: Jurnal Ilmu Komunikasi, 2(2), 189-206. https://doi.org/https://doi.org/10.21070/kanal.v2i2.300

Kusuma, I., Hariadi, S. S., Subejo, \& Mudiyono. (2016). The Absence of the Government Role and the Surviving Strategy of the Scavengers in the Area of Garbage Disposal in Njawar, Benowo, Surabaya, Indonesia. Academic Research International, 7(3), 169-179.

Matindas, K., Hubeis, A. V. S., \& Saleh, A. (2010). Saluran Komunikasi Kelompok Berbasis Gender pada Komunitas Petani Sayuran Organik (Kasus di Megamendung Kabupaten Bogor Provinsi Jawa Barat). Jurnal Komunikasi Pembangunan, 8(1). https://doi.org/10.29244/jurnalkmp.8.1.

Nashruddin, M. (2016). Model Kewirausahaan Agribisnis pada Yayasan Pondok Pesantren Darul Yatama wal Masakin (Yaponpes-Dayama) Jerowaru-Lombok Timur. Palapa, 4(1), 168-177.

Neuman, W. L. (2013). Metodologi penelitian sosial: Pendekatan kualitatif dan kuantitatif. Jakarta: 
PT. Indeks.

Nolan, K. (2012). Dispositions in the field: Viewing mathematics teacher education through the lens of Bourdieu's social field theory. Educational Studies in Mathematics, 80(1-2), 201-215.

Prasetyo, G. A. (2017, July). Berlebaran Di Ladang. Jawa Pos, p. 1 Metropolis.

Rachmad, T. H. (2018). KONTESTASI BUDAYA KOMUNITAS VESPA GEMBELDALAM BUDAYA DOMINAN ISLAMI DI BANGKALAN MADURA. Jurnal Dakwah Tabligh, 18(1), $101-115$.

Rachmat, M., \& Muslim, C. (2012). Rachmat, M., \& Muslim, C. (2012). Dinamika Penguasaan Lahan dan Kelembagaan Kerja Pertanian. Penguasaan Lahan Dan Pragmentasi Lahan, 94-95. Penguasaan Lahan Dan Pragmentasi Lahan, 94-95.

Rakhmat, J. (2005). Psikologi Komunikasi edisi revisi. Bandung: Remaja Rosdakarya.

Rasyid, E., Adriyani, A., \& Darmawan, R. R. (2019). Pengembangan Pertanian Alami Berbasis SelfHelp. Jurnal Ekonomi Pertanian Dan Agribisnis, 3(4), 809-817.

Raya, A. B. (2016). The Influence of Social Network Structure on the Farmer Group Participation in Indonesia. Asian Soc. Sci, 12(3), 119-129.

Rosyidi, M. I. (2018). KOMUNIKASI KELOMPOK DALAM PEMBERDAYAAN MASYARAKAT KAMPUNG KELBUNG PASCA KONFLIK MADURA-SAMPIT. Jurnal Komunikasi, 12(1), $51-62$.

Sasongko, H. A. (2015). VARIASI LEKSIKAL BAHASA JAWA NGOKO MASYARAKAT DESA NGADIREJO KECAMATAN REBAN KABUPATEN BATANG. Skripsi. Universitas Negeri Semarang.

Savage, M., \& Silva, E. B. (2013). Field Analysis in Cultural Sociology. Cultural Sociology, 7(2), 111-126. https://doi.org/10.1177/1749975512473992

Susilowati, S. H. (2016). Gejala Pergeseran Kelembagaan Upah pada Pertanian Padi Sawah. Forum Penelitian Agro Ekonomi, 23(1), 48. https://doi.org/10.21082/fae.v23n1.2005.48-60

Udayan, G., \& Sreedaya, G. S. (2018). Extent of Adoption of House terrace Cultivation of Urban dwellers of Thiruvananthapuram Corporation, Kerala. Journal of Extension Education, 30(1), 6008-6013. https://doi.org/10.26725/jee.2018.1.30.6008-6013

Wacquant, L. (2016). A concise genealogy and anatomy of habitus. The Sociological Review, 64(1), 64-72. https://doi.org/https://doi.org/10.1111/1467-954X.12356 